Savunma Bilimleri Dergisi

The Journal of Defense Sciences

Kasim / Nov 2019, Cilt/Volume 18, Say1/Issue 2.

ISSN (Bas111) : 1303-6831 ISSN (Online): 2148-1776

\title{
Savunma Sanayisinde Aşırı Koşullara Maruz Kalan Hafif Yapısal Malzemelerin Yüzey Modifikasyonu
}

\author{
Hayrani ULUTÜRK* ${ }^{*}$ Uğur MALAYOĞLU** ve Kadir Cihan TEKİN***
}

$\ddot{O} z$

Bu çalışmada, alüminyum oksit, silisyum oksit, wolfram-titanyum karbür ve titanyum karbür parçacıklar ilave edilerek hazırlanan çözeltilerde, plazma elektrolitik oksidasyon (PEO) yöntemiyle AA7075 alaşımı üzerine seramik kaplamalar geliştirilmiştir. Kaplamaların faz bileşimi x-ışııı kırınımı (XRD) yöntemiyle incelenmiştir. Taramalı elektron mikroskobu (SEM) ile kaplamaların yüzey morfolojisi ve kesitin mikroyapısı incelenmiştir. Enerji dağıllımlı $x$-ışını spektrometresi (EDX) sayesinde kaplamaların kimyasal analizi yapılmıştır. Kaplamaların sertlik değerleri mikroVickers sertlik test cihazıyla ölçülmüştür. Kaplama yapılan altlık alaşımların sürtünme ve aşınma davranışını incelemek amacıyla 100Cr6 çelik ve alüminyum oksit bilyelere karşı kuru kaymalı aşınma testleri yapılmıştır. Aşınma testi sonrası yüzey profilometresiyle aşınma profili çıkarılarak aşınan malzeme hacmi hesaplanmıştır. Yapılan testler sonucunda AA7075 alaşımın yüzey sertliği ve aşınma dayanımının üretilen PEO kaplamalarla önemli ölçüde arttı̆̆l gözlenmiştir. Kaplamalar yoğun iç tabaka ve gözenekli üst tabakadan oluşmaktadır. Kaplama sertliğinin altlı/kaplama arayüzeyine yakın bölgede yüksek, yüzeye doğru ilerledikçe gözenekliliğin artışından dolayı düştüğ̈̈ belirlenmiştir. Silisyum oksit parçacık içeren çözeltilerde üretilen kaplamaların diğer kaplamalara göre daha kalın ve pürüzlü olduğu tespit edilmiştir. En düşük aşınma kaybı titanyum karbür içeren çözeltilerde üretilen kaplamada elde edilmiştir.

Anahtar Kelimeler: AA7075, Plazma Elektrolitik Oksidasyon, Nanoparçacık, Sertlik, Aşınma.

* Dokuz Eylül Üniversitesi, Fen Bilimleri Enstitüsü, Nanobilim ve Nanomühendislik Bölümü, hayrani_uluturk@hotmail.com.

** Prof.Dr., Dokuz Eylül Üniversitesi, Mühendislik Fakültesi, Metalurji ve Malzeme Mühendisliği Bölümü, u.malayoglu@gmail.com

*** Dr., Dokuz Eylül Üniversitesi, Mühendislik Fakültesi, Metalurji ve Malzeme Mühendisliği Bölümü, kadir.tekin@deu.edu.tr .

Geliş Tarihi/Received : 13.05.2019

Kabul Tarihi/Accepted : 23.05.2019

Araştırma Makalesi/Research Article 


\title{
Surface Modification of Light Alloys Exposed to Excessive Conditions in the Defense Industry
}

\begin{abstract}
In this study, ceramic coatings were developed on AA7075 alloy by plasma electrolytic oxidation (PEO) method in different solutions prepared by adding aluminum oxide, silicon oxide, wolfram-titanium carbide and titanium carbide particles. The phase composition of the coatings was investigated by $x$-ray diffraction (XRD) method. The surface morphology of the coatings and the microstructure of the cross-section were investigated by scanning electron microscopy (SEM). Chemical analyzes of the coatings were made by means of energy distribution $x$-ray spectrometry (EDX). The hardness values of the coatings were measured by microVickers hardness tester. In order to examine the friction and wear behavior of the coated substrates, dry sliding wear tests were performed against 100Cr6 steel and alumina balls. After the wear test, the wear profile was obtained by the surface profilometer and the material volume loss was calculated. As a result of the tests, it has been observed that the surface hardness and wear resistance of the AA7075 alloy was significantly increased by the application of PEO coatings. The coatings consist of a dense inner layer and a porous outer layer. It has been determined that the coating hardness increased close to substrate/coating interface while decreasing towards the free surface due to the increased porosity. The coatings produced in silicon oxide particle-containing solutions were found to be thicker and rougher than the other coatings. The lowest wear loss was obtained in the coating produced in titanium-carbide-containing solutions.
\end{abstract}

Keywords: AA7075, Plasma Electrolytic Oxidation, Nanoparticle, Hardness, Wear.

\section{Giriş}

Günümüz endüstrisinin vazgeçilmez bir malzemesi olan alüminyum ve alüminyum alaşımları; yüksek özgül mukavemet, düşük yoğunluk ve kolay şekillendirme gibi özelliklerinden dolayı elektronik, havacılık, savunma sanayisi ve benzeri birçok alanda kullanılmaktadır. Ancak düşük aşınma direnci, alüminyum ve alaşımlarının uygulama alanlarını sınırlamaktadır. Bunun yanı sıra, alüminyum 
Savunma Sanayisinde Aşırı Koşullara Maruz Kalan

Hafif Yapısal Malzemelerin Yüzey Modifikasyonu

ve alaşımları kimyasal bileşimlerinden dolayı, korozyona karşı hassastır. Alüminyum alaşımının yukarıda bahsi geçen bu dezavantajlarını minimize etmek için alaşımlandırma, 1sıl işlemler ve yüzey kaplama işlemleri uygulanmaktadır (Davis, 1993; Necşulescu, 2011). Bu işlemler arasından yüzey kaplama işlemleri, alüminyum alaşımlarının çevresel etkilere karşı korunabilmesi, yüzey özelliklerinin iyileştirilmesi amacıyla yaygın olarak kullanılmaktadır (Shibe ve Chawla 2014).

Seramik kaplamalar, alüminyum ve alaşımlarının, mekanik ve yüzey özelliklerinin geliştirilmesi, alüminyum ve alaşımlarının korozyona, aşınmaya ve yüksek sıcaklığa karşı direncinin arttırılması amacıyla kullanılmaktadır. Seramik kaplamalar metaller ile kıyaslandığında daha yüksek sertliğe sahip oldukları için altlık malzemeye yüksek aşınma direnci kazandırır. Ek olarak metal altlığın sahip olduğu kolay şekillendirilebilme ve tokluk gibi bazı özellikleri de korunabilmektedir. Seramik kaplama için kullanılan en yaygın yüzey işlem yöntemleri, anotlama, termal püskürtme, plazma elektrolitik oksidasyon (PEO), kimyasal buhar biriktirme (CVD) ve fiziksel buhar biriktirme (PVD) olarak verilebilir.

Öte yandan PEO veya diğer adıyla mikro ark oksidasyon (MAO), karmaşık şekilli parçaların kaplanmasına imkân veren ve asidik çözelti içermeyen çevreye duyarlı bir kaplama yöntemi olması sebebiyle son yıllarda araştırmacıların ilgi odağı haline gelmiştir. PEO yöntemi, elektrolitik sıvı içerisine daldırılan metallerin ve alaşımlarının yüzeyinde oksit oluşturma ve buna bağlı olarak altlık malzemesinin fiziksel özelliklerinin geliştirilmesi amacıyla uygulanmaktadır. Bu süreç altlık olarak kullanılan alaşımların yüzeylerinde oksit tabakasının biriktirilmesi ve oksit tabakasının büyümesi şeklinde gerçekleşir. Seramik oksit kaplamanın yüksek sertliği sayesinde altlık metalin aşınma direncinde kayda değer seviyede artış gözlenmektedir (Yerokhin vd.,1999).

PEO yönteminde, proses voltaj1, kaplama süresi, elektrolit bileşimi ve nanoparçacıkların ilavesi gibi kaplama özelliklerini etkileyen birçok parametre vardır. Fatimah ve ark.'nın çalışmasında, PEO yöntemi kullanılarak A16061 alaşımı üzerine oluşturulan kaplamada, $\mathrm{SiO}_{2}$ ve $\mathrm{ZrO}_{2}$ nanoparçacıklarının elektrolit içine ilavesiyle çatlakları doldurma ve kaplamalardaki gözenekleri azaltma özelliğine dikkat çekmişlerdir. Nasiri Vatan ve Adabi'nin çalışmasında WC nanoparçacıkların kaplamaların aşınma ve korozyon direncini geliştirdiği 
belirtilmiştir. Arunnellaiappan ve ark'nın çalışmasında $\alpha-\mathrm{Al}_{2} \mathrm{O}_{3}$ nanoparçacıklı PEO numunelerin yüksek korozyon koruması sağladığı belirtilmiştir.

Bu çalışmada; savunma sanayisinde kullanılan AA7075' in PEO yöntemi ile kaplanması, sert ve yüksek aşınma direncine sahip yüzey kaplamaları elde edilmesi hedeflenmektedir. Çözelti içerisine farklı miktarlarda silisyum oksit, alüminyum oksit, wolfram-titanyum karbür ve titanyum karbür parçacıkları ilave edilmiş ve bu parçacıkların kaplama özelliklerine etkisi incelenmiştir.

\section{Malzeme ve Metot}

\section{Parçacıkların Boyutsal Ölçümü}

Üretici firmadan tedarik edilen parçacıkların boyutsal ölçümü için Malvern Panalytical marka Zetasizer Nano ZS cihazı kullanılmıştır. Dinamik 1şık saçılımı ilkesiyle çalışan bu cihazla $0,3 \mathrm{~nm}$ ile $10 \mu \mathrm{m}$ arasındaki nano- ve mikro-boyutlu parçacıkların boyutsal ölçümü yapılmaktadır. Ölçüm öncesinde parçacıkların saf su veya alkol benzeri sıvılar içerisinde topaklanma olmadan dağıtılması gerektiği için alüminyum oksit, titanyum karbür ve wolfram-titanyum karbür parçacıkları, 0,5 g/l sodyum dodesil sülfat (SDS) içeren $50 \mathrm{ml}$ saf su çözeltisine ilave edilerek ultrasonik karıştırıcıyla 10 dakika süresince karıştırılmıştır. Silisyum oksit parçacıkların saf su içerisinde 1slatılabilirliği düşük olduğu için öncelikle etanol içinde spatül yardımıyla mekanik olarak karıştırılmış daha sonra bu karışımın üzerine $0,5 \mathrm{~g} / 1$ sodyum dodesil sülfat (SDS) içeren $50 \mathrm{ml}$ saf su çözeltisi ilave edilerek ultrasonik karıştırıcıyla 10 dakika boyunca karıştırılmıştır. Parçacıkları içeren çözeltiden belirli bir miktar şırıngayla alınarak cihazın ölçüm kabına aktarılmış ve boyut dağılımı ölçülmüştür.

\section{PEO Kaplama İşlemi}

AA7075 alüminyum alaşımından üretilmiş $25 \mathrm{~mm}$ çapında silindir çubuk, $\mathrm{SiC}$ kesme diski ile $10 \mathrm{~mm}$ kalınlığında parçalara ayrılarak altlık numuneleri elde edilmiştir. Numunelerin yüzeyleri sirasiyla 240, 400, 800 ve 1200 grit su zımparasıyla zımparalanıp daha sonra asetonla ultrasonik banyoda temizlenmiş ve sıcak havayla kurutulmuştur. Kaplama ana çözeltisinde $7 \mathrm{~g} / 1$ sodyum metasilikat pentahidrat $\left(\mathrm{Na}_{2} \mathrm{SiO}_{3} \cdot 5 \mathrm{H}_{2} \mathrm{O}\right), 4 \mathrm{~g} / \mathrm{l}$ potasyum hidroksit $(\mathrm{KOH})$ ve $2,7 \mathrm{~g} / \mathrm{l}$ potasyum 
Savunma Sanayisinde Aşırı Koşullara Maruz Kalan

Hafif Yapısal Malzemelerin Yüzey Modifikasyonu

sodyum tartarat tetrahidrat $\left(\mathrm{C}_{4} \mathrm{H}_{4} \mathrm{KNaO}_{6} \cdot 4 \mathrm{H}_{2} \mathrm{O}\right)$ kullanılmıştır. Parçacık takviyeli kaplamaları hazırlamak için, öncelikle $100 \mathrm{ml}$ saf su içerisine parçacıkların topaklanmadan dağılmasını sağlamak amacıyla 0,5 g/l SDS ilave edilmiştir. Hazırlanan bu çözeltiye alüminyum oksit, titanyum karbür ve wolfram-titanyum karbür parçacıkları, $1 \mathrm{~g} / 1$ ve $3 \mathrm{~g} / 1$ derişimlerinde ilave edilmiştir. Silisyum oksit parçacıkların saf su içerisinde islatılabilirliği düşük olduğu için öncelikle etanol içinde spatül yardımıyla mekanik olarak karıştırılmış daha sonra SDS içeren saf su içerisine diğer nanoparçacıklarla aynı oranlarda ilave edilmiştir. Hazırlanan parçacık ilaveli çözeltiler Bandelin Sonopuls ultrasonik homojenizatör yardımıyla 4 dakika boyunca karıştırılmıştır. Daha sonra parçacık ilaveli çözelti ayrıca hazırlanan ana çözelti içerisine eklenerek 20 dakika boyunca ultrasonik olarak karıştırılmıştır. Kaplama işleminde alternatif akım (AC) kaynağına ve çözelti banyosuna sahip Keronite G2 kaplama ünitesi kullanılmıştır. Kaplama banyosuna daldırılan altlık numuneye 10 dakika süresince $20 \mathrm{~A} / \mathrm{dm}^{2}$ sabit akım yoğunluğu uygulanmış sonraki 50 dakika boyunca akım yoğunluğu azaltılarak işlem sonlandırılmıştır. İşlem sonrası numune saf suyla yıkanıp sıcak havayla kurutulmuştur. PEO kaplama işlemine ait detaylı bilgiler Tablo 1'de verilmiştir.

Tablo 1. PEO İşleminde Kullanılan Çözeltilerin İçeriği ve Kaplama İşlem

Parametreleri

\begin{tabular}{|c|c|c|c|c|}
\hline $\begin{array}{l}\text { Kaplama } \\
\text { Kodu }\end{array}$ & $\begin{array}{l}\text { Parçacık Takviyesi ve } \\
\text { Derişimi }\end{array}$ & $\begin{array}{l}\text { Ana } \\
\text { İçeriği }\end{array}$ & $\begin{array}{l}\text { Kaplama } \\
\text { İşlem } \\
\text { Süresi }\end{array}$ & $\begin{array}{l}\text { Uygulanan } \\
\text { Akım } \\
\text { Yoğunluğu }\end{array}$ \\
\hline Katk1s1Z & - & \multirow{7}{*}{$\begin{array}{l}7 \mathrm{~g} / 1 \text { sodyum } \\
\text { metasilikat } \\
\text { pentahidrat, } \\
4 \mathrm{~g} / 1 \text { potasyum } \\
\text { hidroksit, } \\
2,7 \mathrm{~g} / 1 \text { potasyum } \\
\text { sodyum tartarat } \\
\text { tetrahidrat }\end{array}$} & \multirow{7}{*}{60 dakika } & \multirow{7}{*}{$\begin{array}{l}20 \mathrm{~A} / \mathrm{dm}^{2}- \\
10 \text { dakika } \\
<20 \mathrm{~A} / \mathrm{dm}^{2}- \\
50 \text { dakika }\end{array}$} \\
\hline SO-1 & Silisyum oksit, $1 \mathrm{~g} / \mathrm{l}$ & & & \\
\hline SO-3 & Silisyum oksit, $3 \mathrm{~g} / \mathrm{l}$ & & & \\
\hline AO-1 & $\begin{array}{l}\text { Alüminyum oksit, } 1 \\
\text { g/l }\end{array}$ & & & \\
\hline $\mathrm{AO}-3$ & $\begin{array}{l}\text { Alüminyum oksit, } 3 \\
\text { g/l }\end{array}$ & & & \\
\hline WTC-1 & $\begin{array}{l}\text { Wolfram-titanyum } \\
\text { karbür, } 1 \mathrm{~g} / 1\end{array}$ & & & \\
\hline TC-1 & Titanyum karbür, $1 \mathrm{~g} / 1$ & & & \\
\hline
\end{tabular}




\section{Kaplamaların Yapısal İncelemesi}

Kaplamaların yüzey pürüzlülüğü Ambios XP-2 yüzey profilometresinde ölçülmüştür. Kaplamaların yüzey morfolojisinin incelenmesi ve arakesit mikroyapı görüntülerinin elde edilmesi için JEOL 6060 taramalı elektron mikroskobu (SEM) kullanılmıştır. Kaplanmış numuneler kesme diskiyle kesilip epoksi reçineyle kalıba alınarak arakesit incelemesi için numuneler hazırlanmıştır. Daha sonra zımparalama ve elmasla parlatma işlemlerinden geçirilerek SEM incelemesi öncesinde kesit yüzeyi altın filmle kaplanmıştır. Kaplamaların kimyasal analizi için enerji dağılımlı x-1şını spektrometresi (EDX) kullanılmıştır. Parçacıkların ve kaplamaların faz analizi Rigaku D-Max X-ışını difraktometresiyle yapılmıştır.

\section{Sertlik Ölçümü}

Altlık alaşımın ve kaplamaların sertlik değerleri, Shimadzu mikroVickers sertlik cihazında $0,025 \mathrm{~kg}$ yük uygulanarak ölçülmüştür. Sertlik ölçümü ara kesit numunelerinde kaplama kalınlığı boyunca belirli mesafe aralıklarında iz vurularak yapılmıştır.

\section{Aşınma Testi}

Altlık alaşım ve kaplanmış numunelerin aşınma testlerinde CSM Instruments marka standart tribometre kullanılmıştır. Kuru kaymalı aşınma testleri $10 \mathrm{~N}$ sabit yük altında, $10 \mathrm{~mm}$ stroke mesafesiyle, $6 \mathrm{~mm}$ çapındaki $100 \mathrm{Cr} 6$ çelik ve alüminyum oksit bilyelere karşı yapılmıştır. Toplam aşınma mesafesi ve kayma hızı sırasıyla $200 \mathrm{~m}$ ve $0,06 \mathrm{~m} / \mathrm{s}$ olarak belirlenmiştir. Aşınma testi sonrasında altlık numunelerin ve bilyelerin aşınan yüzeyleri optik mikroskop altında incelenmiştir. Kaplanmış numuneyle yapılan aşınma testlerinde, çelik bilye üzerinde oluşan aşınma izinin çapı ölçülerek ASTM G99 test standardına göre hacim kaybı hesaplanmıştır. Altlık alaşımın ve kaplamaların aşınma izinin profili Ambios XP-2 yüzey profilometresiyle çıkarılmış ve aşınma sonrası hacimsel malzeme kaybı hesaplanmıştır. 
Savunma Sanayisinde Aşırı Koşullara Maruz Kalan

Hafif Yapısal Malzemelerin Yüzey Modifikasyonu

\section{Test Sonuçları ve Tartışma}

\section{Parçacıkların Boyutsal Ölçümü}

Parçacıkların boyutsal dağılımı ve yüzdeleri Şekil 1'de gösterilmiştir. Silisyum oksit, alüminyum oksit, wolfram-titanyum karbür ve titanyum karbür parçacıkların ortalama boyutları sırasıyla $272 \mathrm{~nm}, 1493 \mathrm{~nm}, 417 \mathrm{~nm}$ ve $195 \mathrm{~nm}$ ölçülmüştür. En düşük parçacık boyutuna sahip malzemenin titanyum karbür olduğu ayrıca diğer malzemelere kıyasla alüminyum oksidin ortalama boyutunun mikro ölçekte olduğu tespit edilmiştir.
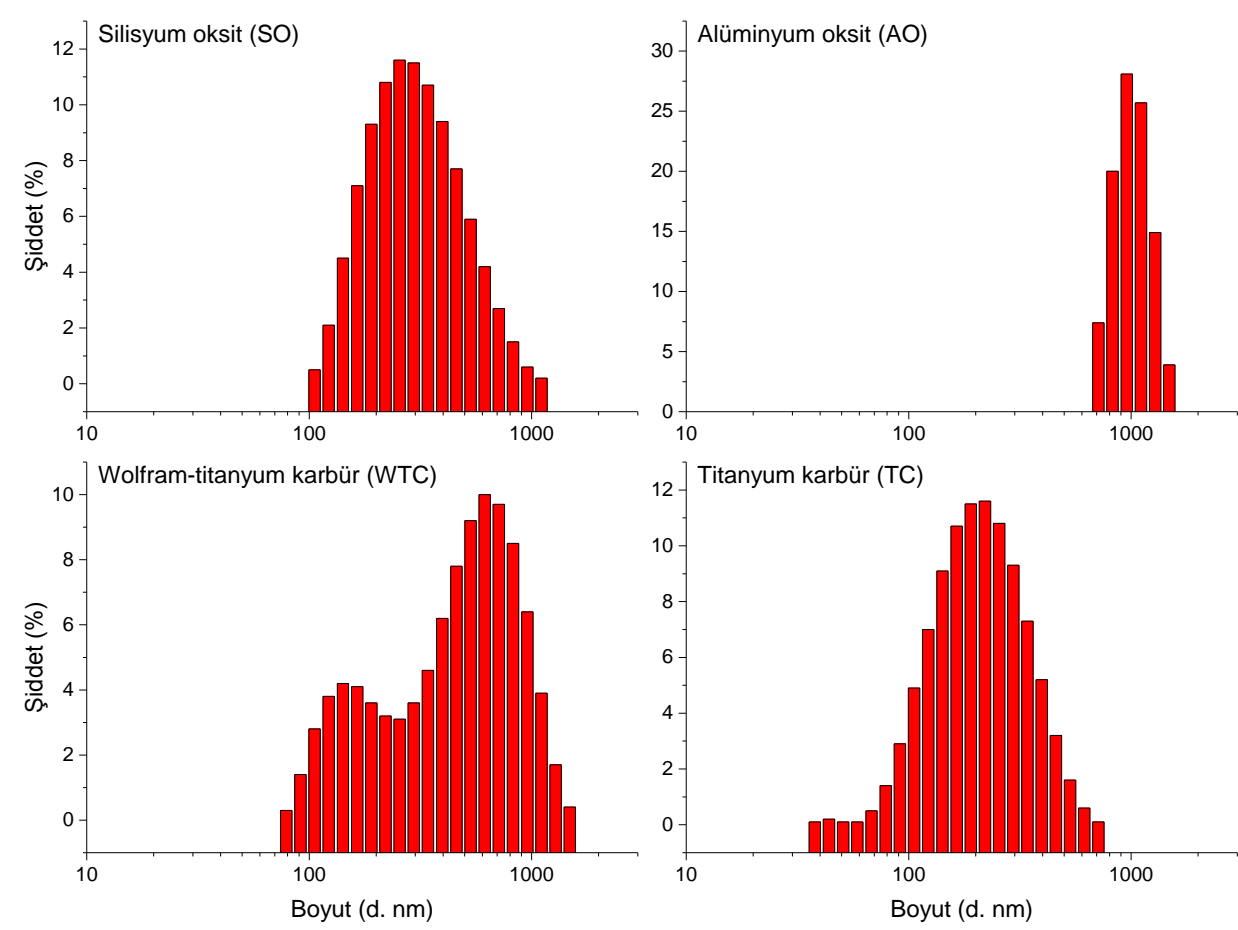

Şekil 1. Parçacıkların Tane Boyutu Analizi Sonuçları 


\section{XRD Analizi}

Şekil 2'deki parçacıkların XRD analiz sonuçları incelendiğinde, silisyum oksit malzemenin spektrumunda kristalin faza ait herhangi pik olmadığı, sadece $10^{\circ}-30^{\circ}$ arasında geniş bir tepenin olduğu tespit edilmiştir. Bu sonuca göre silisyum oksit malzemenin amorf yapıda olduğu ortaya çıkmıştır. Alüminyum oksit malzemenin çoğunlukla $\alpha-\mathrm{Al}_{2} \mathrm{O}_{3}$ ve çok az miktarda $\beta-\mathrm{Al}_{2} \mathrm{O}_{3}$, titanyum karbür malzemenin $\mathrm{TiC}$, ve wolfram-titanyum karbür malzemenin $\mathrm{C}_{5} \mathrm{Ti}_{4} \mathrm{~W}$ kristalin faz yapılarına sahip olduğu belirlenmiştir.
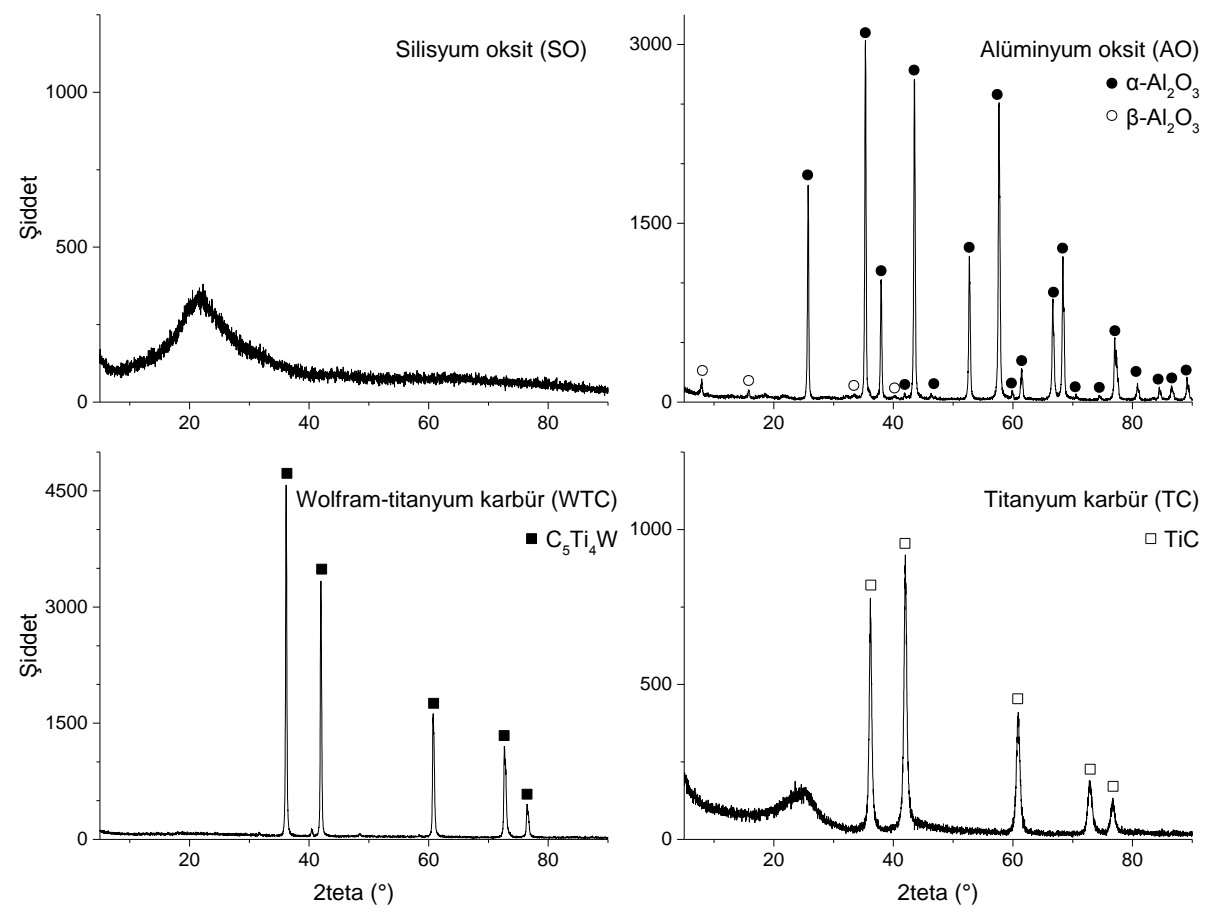

Şekil 2. PEO İşleminde Kullanılan Parçacıkların XRD Analizi Sonuçları

PEO kaplama yapılan numunelerin XRD spektrumları ve analiz sonuçları Şekil 3 ve Tablo 2'de gösterilmiştir. X-ışınları kaplamadan geçerek altlık alaşıma ulaşabildiği için XRD spektrumunda alüminyum metaline ait pikler görülmektedir. Tüm kaplamalarda, altlık alaşımda bulunan alüminyumun oksitlenerek sinterlenmesi sonucunda yarı-kararlı $\gamma-\mathrm{Al}_{2} \mathrm{O}_{3}$ fazının oluştuğu gözlenmiştir. Yarı- 
Savunma Sanayisinde Aşırı Koşullara Maruz Kalan

Hafif Yapısal Malzemelerin Yüzey Modifikasyonu

kararlı $\gamma-\mathrm{Al}_{2} \mathrm{O}_{3}$ fazı $1050{ }^{\circ} \mathrm{C}$ sıcaklığın üzerinde termodinamik açıdan kararlı olan $\alpha-\mathrm{Al}_{2} \mathrm{O}_{3}$ fazına dönüşmektedir (Lamouri vd., 2017). Yapılan analizlerde kararlı $\alpha$ $\mathrm{Al}_{2} \mathrm{O}_{3}$ fazına ait piklerin şiddeti $\gamma-\mathrm{Al}_{2} \mathrm{O}_{3}$ fazına kıyasla daha az olduğu için kaplama yapısında daha az miktarda bulunduğu tespit edilmiştir. SDS ile çevrelenmiş negatif yüklü alüminyum oksit parçacıkları PEO işlemi sırasında anot yüzeyine yönlenerek kaplama içerisine dahil olması sonucunda AO-1 ve AO-3 kaplamaların yapısındaki $\alpha-\mathrm{Al}_{2} \mathrm{O}_{3}$ miktarının arttı̆̆ 1 ortaya çıkmıştır. Silisyum oksit parçacık içeren çözeltide üretilen kaplamalarda, özellikle SO-1 kaplamanın yapısında müllit fazının olduğu tespit edilmiştir. Ana kaplama çözeltisinde sodyum metasilikat pentahidrat olmasına karşın diğer kaplamalarda müllit fazı tespit edilmemiştir. Bu nedenle amorf silisyum oksit parçacıkların kaplama içerisine dahil olup alüminyum oksitle reaksiyona girmesi sonucunda müllit fazını oluşturduğu düşünülmektedir. PEO işleminde plazma deşarjı sırasında plazma termokimyasal ve elektrokimyasal reaksiyonlar meydana gelir. Çözelti içerisindeki yüzey aktif maddeyle çevrelenmiş halde olan amorf silisyum oksit parçacıkları, elektriksel alan kuvvetiyle alüminyum yüzeyine doğru hareket ederek kaplamanın yüzeyinde birikir. Amorf yapıdaki silisyum oksit parçacıklar, plazma deşarjının ürettiği yüksek sıcaklık nedeniyle yarı-kararlı $\gamma$-A12O3 fazının içerisine doğru yayınır ve bunun sonucunda müllit $\left(3 \mathrm{Al}_{2} \mathrm{O}_{3} \cdot 2 \mathrm{SiO}_{2}\right)$ fazının oluşması sağlanır (Xin vd., 2006). Diğer taraftan, SO-3 kaplamada, çözelti içerisindeki parçacık derişimi yüksek olduğundan daha fazla amorf silisyum oksidin biriktiği ve kristalin fazlara ait piklerin şiddetinin bu nedenle azaldığı düşünülmektedir. WTC-1 kaplamada çözelti içerisindeki $\mathrm{C}_{5} \mathrm{Ti}_{4} \mathrm{~W}$ faz yapısındaki parçacıkların faz dönüşümüne uğramadan yapıya dahil olduğu gözlenmiştir. 


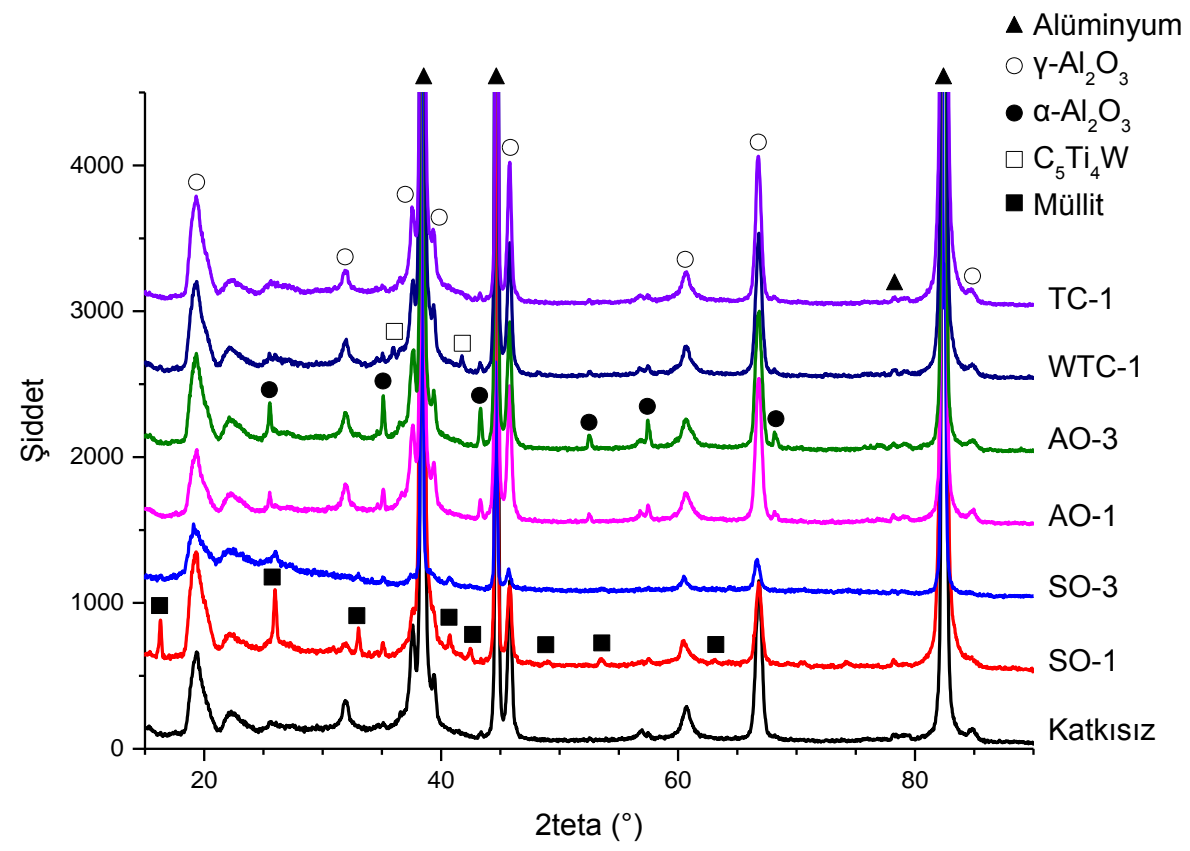

Şekil 3. PEO Kaplamaların XRD Analizi Sonuçları

Tablo 2. Elde Edilen XRD Sonuçlarına Göre Kaplamaların İçerdiği Fazlar

\begin{tabular}{|l|l|}
\hline Kaplamalar & İçerdiği Fazlar \\
\hline Katkısız & $\gamma-\mathrm{Al}_{2} \mathrm{O}_{3}, \alpha-\mathrm{Al}_{2} \mathrm{O}_{3}$ \\
\hline SO-1 & $\gamma-\mathrm{Al}_{2} \mathrm{O}_{3}, \alpha-\mathrm{Al}_{2} \mathrm{O}_{3}$, Müllit \\
\hline SO-3 & $\gamma-\mathrm{Al}_{2} \mathrm{O}_{3}, \alpha-\mathrm{Al}_{2} \mathrm{O}_{3}$, Müllit \\
\hline AO-1 & $\gamma-\mathrm{Al}_{2} \mathrm{O}_{3}, \alpha-\mathrm{Al}_{2} \mathrm{O}_{3}$ \\
\hline AO-3 & $\gamma-\mathrm{Al}_{2} \mathrm{O}_{3}, \alpha-\mathrm{Al}_{2} \mathrm{O}_{3}$ \\
\hline WTC-1 & $\gamma-\mathrm{Al}_{2} \mathrm{O}_{3}, \alpha-\mathrm{Al}_{2} \mathrm{O}_{3}, \mathrm{C}_{5} \mathrm{Ti}_{4} \mathrm{~W}$ \\
\hline TC-1 & $\gamma-\mathrm{Al}_{2} \mathrm{O}_{3}, \alpha-\mathrm{Al}_{2} \mathrm{O}_{3}$ \\
\hline
\end{tabular}

\section{SEM Analizi}

Kaplamaların arakesit görüntüleri Şekil 4'de gösterilmektedir. Kesit görüntülerinden ölçülen kaplama kalınlıkları ve profilometreyle ölçülen pürüzlülük değerleri Tablo 3'de verilmiştir. Kaplamaların geneline bakıldığında, yoğun alt 
Savunma Sanayisinde Aşırı Koşullara Maruz Kalan

tabaka ile göreceli olarak daha gözenekli ve pürüzlü üst tabakadan meydana geldikleri görülmektedir. Çözeltiye parçacık ilavesi yapılmasıyla yüzey pürüzlülüğünün arttığı gözlenmiştir. Katkısız kaplamayla karşılaştırıldığında, silisyum oksit parçacık içeren çözeltide üretilen kaplamaların kalınlığının önemli ölçüde arttığ1 ancak diğer parçacık malzemelerin ilavesiyle elde edilen kaplamaların neredeyse benzer kalınlığa sahip oldukları tespit edilmiştir. SO-1 ve SO-3 kaplamalar birbiriyle kıyaslandığında, artan parçacık derişimiyle daha az gözenekli ve kalın bir alt tabakanın oluştuğu, ancak üst tabakanın daha gözenekli ve pürüzlü hale geldiği belirlenmiştir.
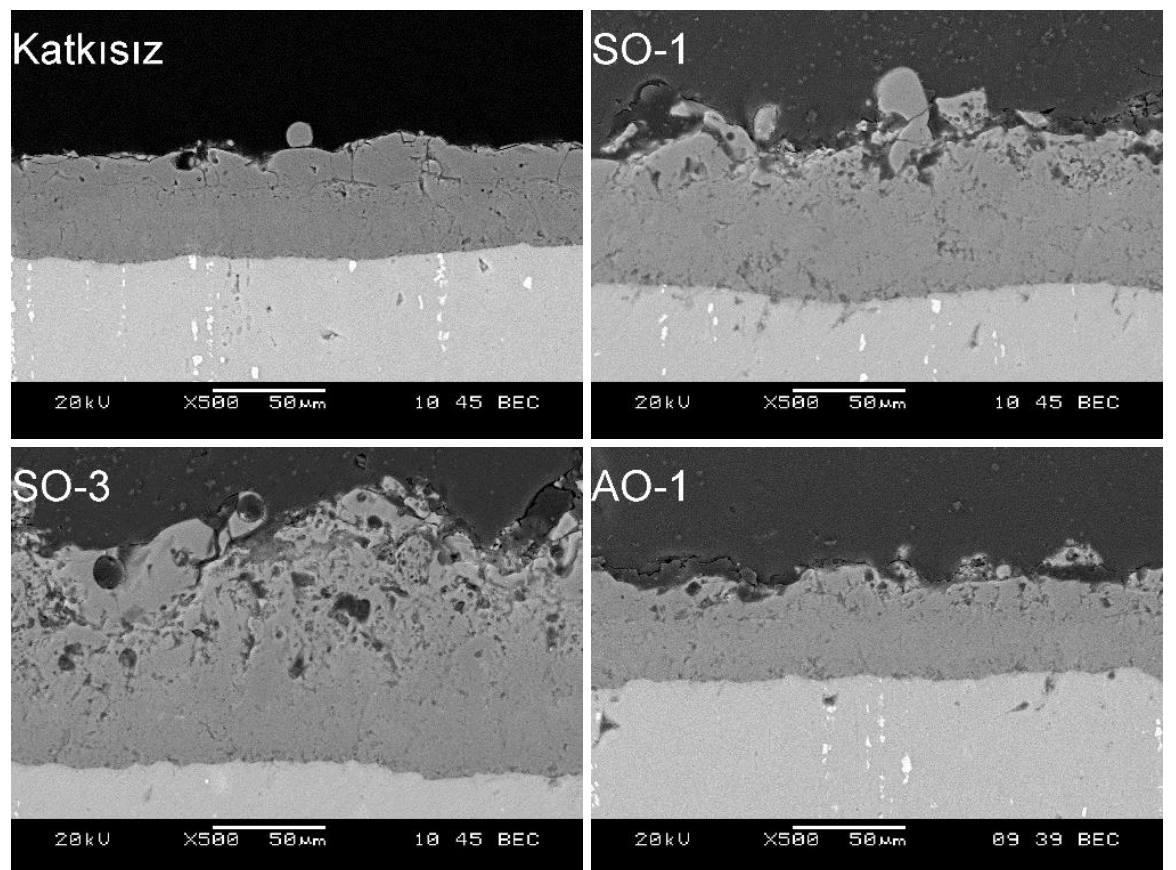

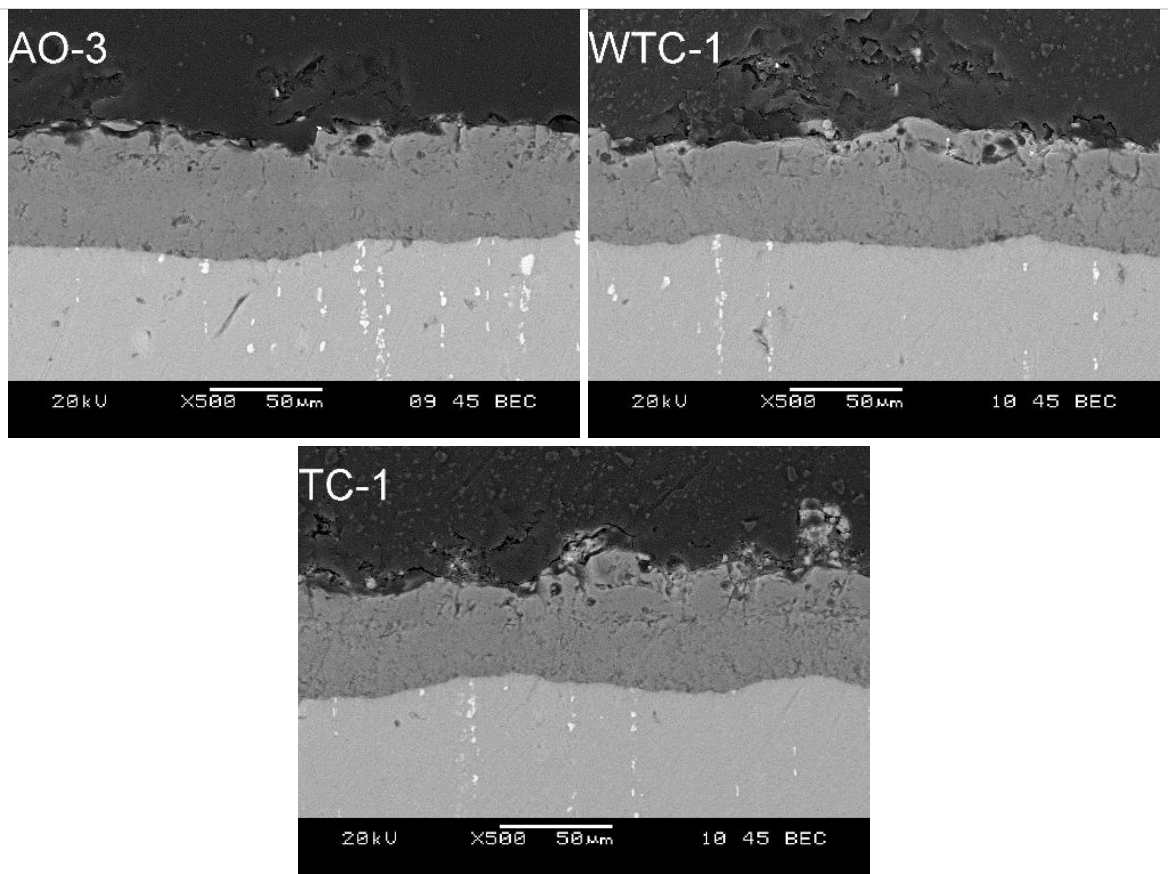

Şekil 4. Kaplamaların Arakesit Görüntüleri

Tablo 3. Kaplama Kalınlıkları ve Yüzey Pürüzlülüğü Değerleri

\begin{tabular}{|l|l|l|l|l|l|l|l|}
\hline & Katkısız & SO-1 & SO-3 & AO-1 & AO-3 & WTC-1 & TC-1 \\
\hline Kalınlık $(\mu \mathrm{m})$ & 49,1 & 64,3 & 107,3 & 46,6 & 49,2 & 49,1 & 48,5 \\
\hline $\operatorname{Ra}(\mu \mathrm{m})$ & 4,22 & 8,10 & 13,03 & 4,91 & 5,53 & 5,91 & 6,28 \\
\hline
\end{tabular}

EDX yöntemiyle kaplamaların yüzeyinden alınan kimyasal analiz sonuçları Tablo 4'de verilmiştir. Tüm kaplamalarda silisyum elementinin bulunması ana çözeltideki silikat iyonlarının $\left(\mathrm{SiO}_{3}{ }^{2-}\right)$ yüksek oranda yapıya katıldığını göstermektedir. SO-1 ve SO-3 kaplamalarda amorf silisyum oksit silikat iyonlarıyla birlikte yapıya katıldığı için katkısız kaplamaya kıyasla daha yüksek miktarda silisyum içerdiği ve alüminyum içeriğinin azaldığı gözlenmiştir. Çözeltideki $\alpha-\mathrm{Al}_{2} \mathrm{O}_{3}$ parçacıkların oranı arttıkça yapıya dahil olan silisyumun azaldığ1 diğer taraftan alüminyumun arttı̆̆1 görülmüştür. WTC-1 ve TC-1 kaplamalarda çözelti içerisinden wolfram ve titanyum içeren parçacıkların yapıya dahil olduğu görülmektedir. 
Savunma Sanayisinde Aşırı Koşullara Maruz Kalan

Hafif Yapısal Malzemelerin Yüzey Modifikasyonu

Tablo 4. Kaplamaların Yüzeyinden Alınan EDX Analizi Sonuçları

\begin{tabular}{|c|c|c|c|c|c|c|c|}
\hline $\begin{array}{c}\text { Element } \\
(\% \text { ağ. })\end{array}$ & Katk1siz & SO-1 & SO-3 & AO-1 & AO-3 & WTC-1 & TC-1 \\
\hline $\mathrm{O}$ & 18,94 & 20,5 & 23,26 & 19,93 & 19,52 & 17,93 & 18,41 \\
\hline $\mathrm{Na}$ & 0,61 & 0,77 & 0,81 & 0,24 & 0,19 & 0,38 & 0,81 \\
\hline $\mathrm{Mg}$ & 1,02 & 0,56 & 0,31 & 0,82 & 0,78 & 0,78 & 0,74 \\
\hline $\mathrm{Al}$ & 42,37 & 27,75 & 16,63 & 44,73 & 49,06 & 36,8 & 32,29 \\
\hline $\mathrm{Si}$ & 29,3 & 42,04 & 52,03 & 27,77 & 23,39 & 26,69 & 27,98 \\
\hline $\mathrm{K}$ & 4,8 & 5,79 & 5,58 & 3,46 & 4,44 & 4,17 & 4,93 \\
\hline $\mathrm{Ti}$ & - & - & & & - & 1,16 & 6,38 \\
\hline $\mathrm{Zn}$ & 2,96 & 2,59 & 1,38 & 3,05 & 2,62 & 2,88 & 2,24 \\
\hline $\mathrm{W}$ & - & - & - & & - & 4,93 & - \\
\hline $\mathrm{C}$ & - & - & - & & - & 4,28 & 6,22 \\
\hline
\end{tabular}

SO-1 ve SO-3 kaplamaların kesiti boyunca alüminyum ve silisyumun miktarının göreceli olarak değişimi Şekil 5'de verilmiştir. Silisyumun yüzeye yakın bölgelerde yüksek oranda bulunduğu ve altlığa doğru ilerledikçe miktarının azaldığı ortaya çıkmıştır. Diğer taraftan alüminyumun silisyuma göre tam tersi bir profile sahip olduğu görülmektedir. Bu sonuçlara bakıldığında, kaplamaların yüzeyine yakın bölgede parçacıkların daha fazla biriktiği ortaya çıkmıştır. Kaplamada plazma deşarjı esnasında altlık malzeme oksitlenir ve ergiyik halde yüksek basıncın etkisiyle çözelti/kaplama arayüzeyine doğru hareket eder. Bu esnada çözeltideki iyonlar ve parçacıklar elektriksel alanın etkisiyle plazma deşarj kanalı içerisine doğru hareket ederek plazma içindeki ergimiş oksit malzemeyle birleşerek yüzeyde katılaşır ve birikir. Arakesit görüntülerindeki kalınlık artışı ve EDX sonuçları incelendiğinde kaplama içerisine en fazla silisyum oksit parçacıkların dahil olduğu görülmektedir. 

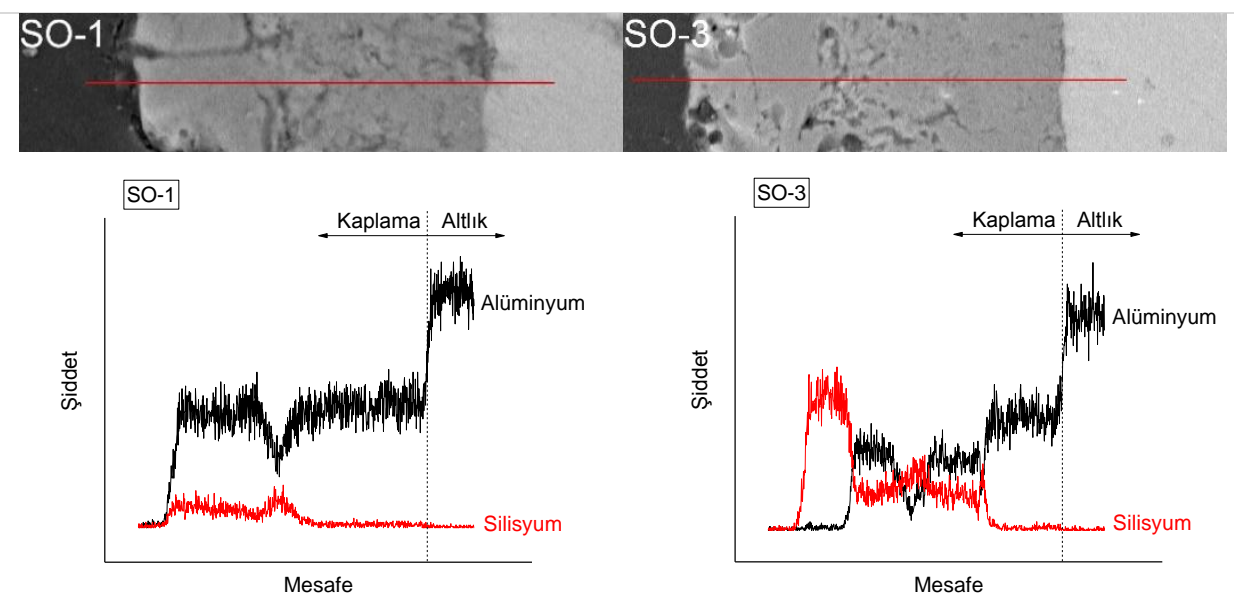

Şekil 5. SO-1 ve SO-3 Kaplamaların Kesitinde Kalınlık Boyunca Alüminyum ve Silisyum Miktarının Değişimi

\section{Sertlik Ölçümü Sonuçları}

Kaplamaların kesiti boyunca belirli aralıklarla ölçülen mikroVickers sertlik değerleri Şekil 6'te gösterilmiştir. Altlık AA7075 alaşımıyla karşılaştırıldığında, kaplamaların yapısında kristalin seramik fazların bulunması sayesinde sertlik değerlerinin kayda değer oranda arttığı görülmektedir. Kaplamaların altlığa yakın olan bölgesinde sertliğin yüksek, yüzeye yakın bölgelerde ise düşük olduğu belirlenmiştir. Bunun temel sebebi arakesit görüntülerinde görüldüğü üzere kaplama/altlık arayüzeyinden yüzeye doğru ilerledikçe kaplama gözenekliliğinin artmasıdır (Krell ve Schädlich, 2001). SO-1 ve SO-3 kaplamalarda yüzeye yakın bölgede gözeneklilik arttığı için mesafeye bağlı sertlik düşüşü diğer kaplamalara kıyasla daha fazladır. Sertliğin SO-1 ve SO-3 kaplamalarda aşırı düşmesinin diğer bir sebebi olarak yüzeye yakın bölgede amorf silisyum oksit ve müllit fazının oluşumu gösterilebilir. Amorf silisyum oksit (7,12 Gpa) ve müllit (15 Gpa) fazlarının sertliğinin, alüminyum oksit (korund: $23 \mathrm{Gpa}$ ) malzemenin sertliğinden daha düşük olduğu bilinmektedir (Kollenberg ve Schneider, 1989; Pitchford vd., 2004; McColm, 1990). 


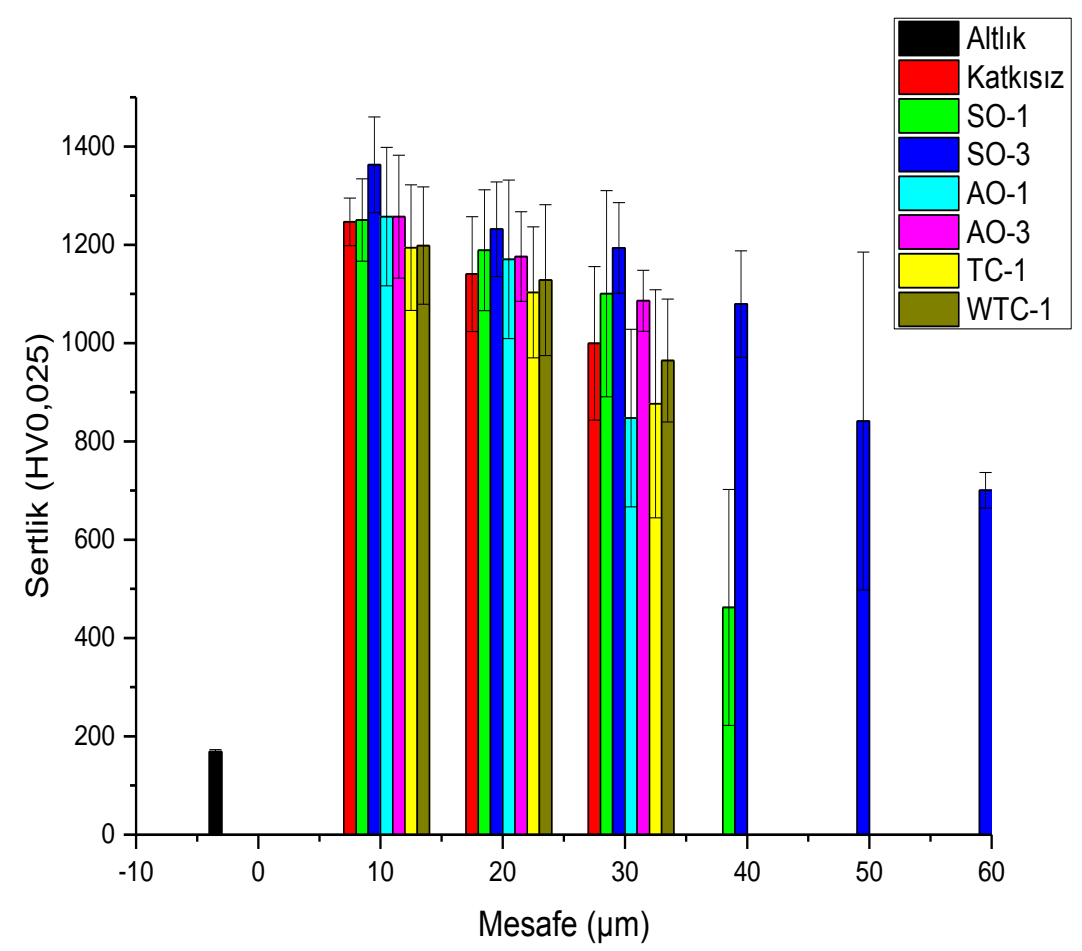

Şekil 6. Kaplamaların Kesitten Kalınlık Boyunca Ölçülen Sertlik Değerleri

\section{Aşınma Testi Sonuçları}

AA7075 altlık alaşımı ile kaplamaların aşınma hızı değerleri ve aşınma izi profilleri sırasıyla Şekil 7 ve Şekil 8'de verilmiştir. Ayrıca aşınma testi sonrasında katkısız kaplama ve altlık alaşımın yüzeylerinde çelik ve alüminyum oksit bilyelerin oluşturduğu aşınma izlerinin optik mikroskop görüntüleri Şekil 9'da gösterilmiştir. Kaplamasız AA7075 alaşımı, çelik ve alüminyum oksit bilyelere kıyasla düşük yüzey sertliğine sahip olduğu için aşınma testi sırasında temas yüzeyinde oluşan kayma gerilmelerinin etkisiyle aşırı plastik deformasyona uğrar ve adeziv aşınmaya maruz kalır. Buna ilave olarak sert aşındırıcı bilye, abraziv aşınmaya sebep olarak altıkta ciddi oranda malzeme kaybına yol açmaktadır. 
Altlık alaşımın yüzeyinde oluşan aşınma izi incelendiğinde abraziv aşınmayı gösteren derin çizikler görülmekte ve izin kenarlarında metal malzemenin plastik deformasyonu sonucunda yığılmaların oluştuğu tespit edilmiştir. Diğer taraftan kalın ve sert kaplamanın yük taşıma kapasitesi yüksek olduğu için aşınma testi boyunca yüzeye yakın bölgede oluşan kayma gerilmelerini içerisinde tutar. Bunun sonucunda altlık alaşımın bilyeyle temasını önler ve aşınma direncini arttırır. Alüminyum oksit bilyenin oluşturduğu aşınma izi profilleri incelendiğinde, tüm kaplamaların aşınma testi boyunca altlık yüzeyinde tutunarak alüminyum alaşımın aşırı malzeme kaybına uğramasını önlediği gözlenmektedir. Alüminyum oksit bilyenin yüzeyinde oluşan iz, aşınma kaybını hesaplamak için uygun geometriye sahip olmamasına rağmen, bilye üzerindeki aşınma yönüne paralel çiziklerin varlığı kaplamanın bilyeyi belli bir miktar aşındırdığını göstermektedir. 100Cr6 çelik bilyeyle yapılan testlerde asıl aşınma kaybının çelik malzemede olduğu görülmüş ancak kaplamanın yüzey profilinde herhangi bir aşırı malzeme kaybı bulgusuna rastlanmamıştır. Aşınma izleri incelendiğinde çelik bilyenin düz ve çizikli bir aşınma yüzeyine sahip olduğu tespit edilmiştir. Bunun temel nedeni sert PEO kaplama üzerinde bulunan çıkıntıların çeliğin yüzeyinden abraziv aşınmayla malzeme koparmasıdır. Çelik bilye aşırı malzeme kaybına uğrarken kaplama yüzeyindeki çıkıntılar düzleşip sadece ihmal edilebilir düzeyde malzeme kaybına uğramaktadır. SO-1 ve SO-3 kaplamaların diğer kaplamalara kıyasla daha fazla malzeme kaybına uğradığı görülmüştür. Bunun nedeni, SO kaplamaların üst tabakasında gözenekliliğin artmasıyla sertliğin düşmesi ve kaplama içindeki kohezyon kuvvetlerinin azalmasıdır. SO haricindeki kaplamaların aşınma hızları benzer olmakla birlikte en düşük aşınma hızı TC-1 kaplamada elde edilmiştir. 
Savunma Sanayisinde Aşırı Koşullara Maruz Kalan

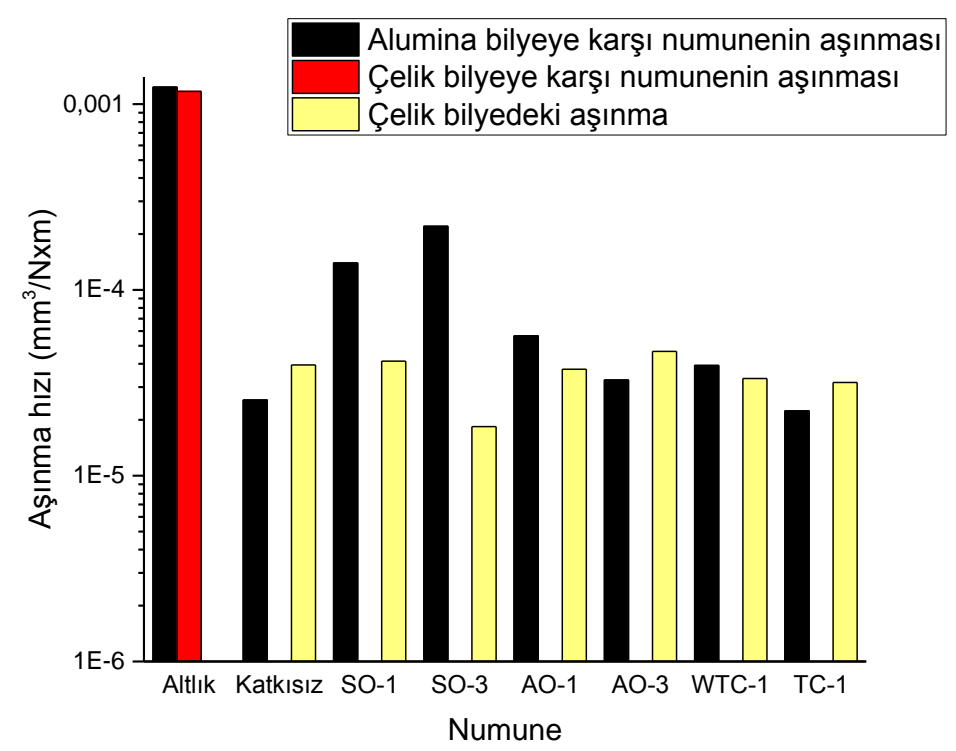

Şekil 7. Altlık Alaşım, Kaplamaların ve Çelik Bilyenin Aşınma Hızı Değerleri

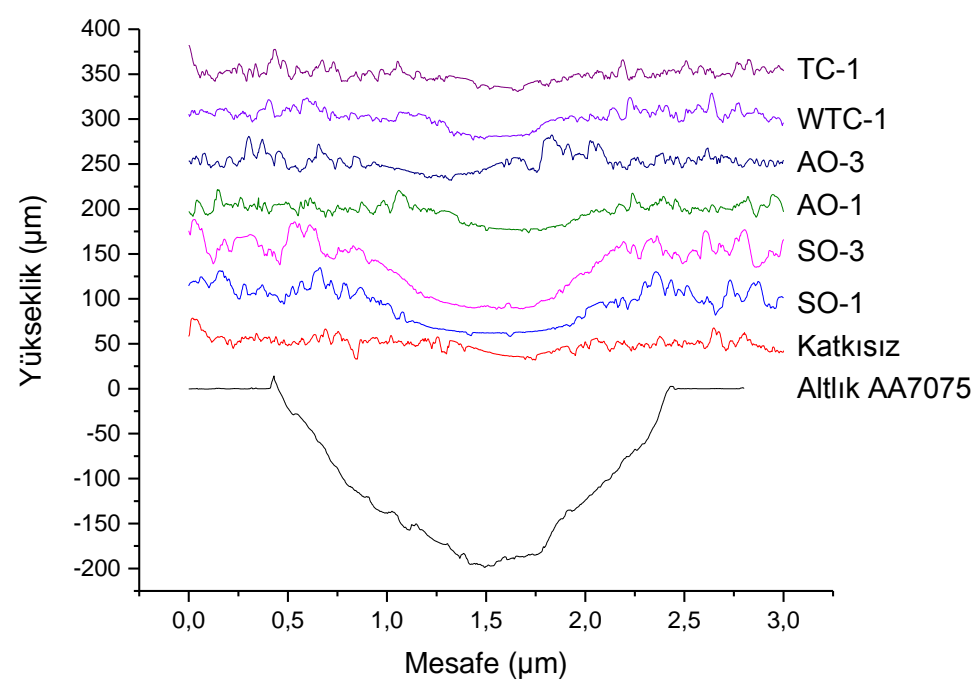

Şekil 8. Alüminyum Oksit Bilyeye Karşı Yapılan Testlerde Altlık AA7075 ve Kaplamaların Yüzeyinde Oluşan Aşınma İzi Profilleri 

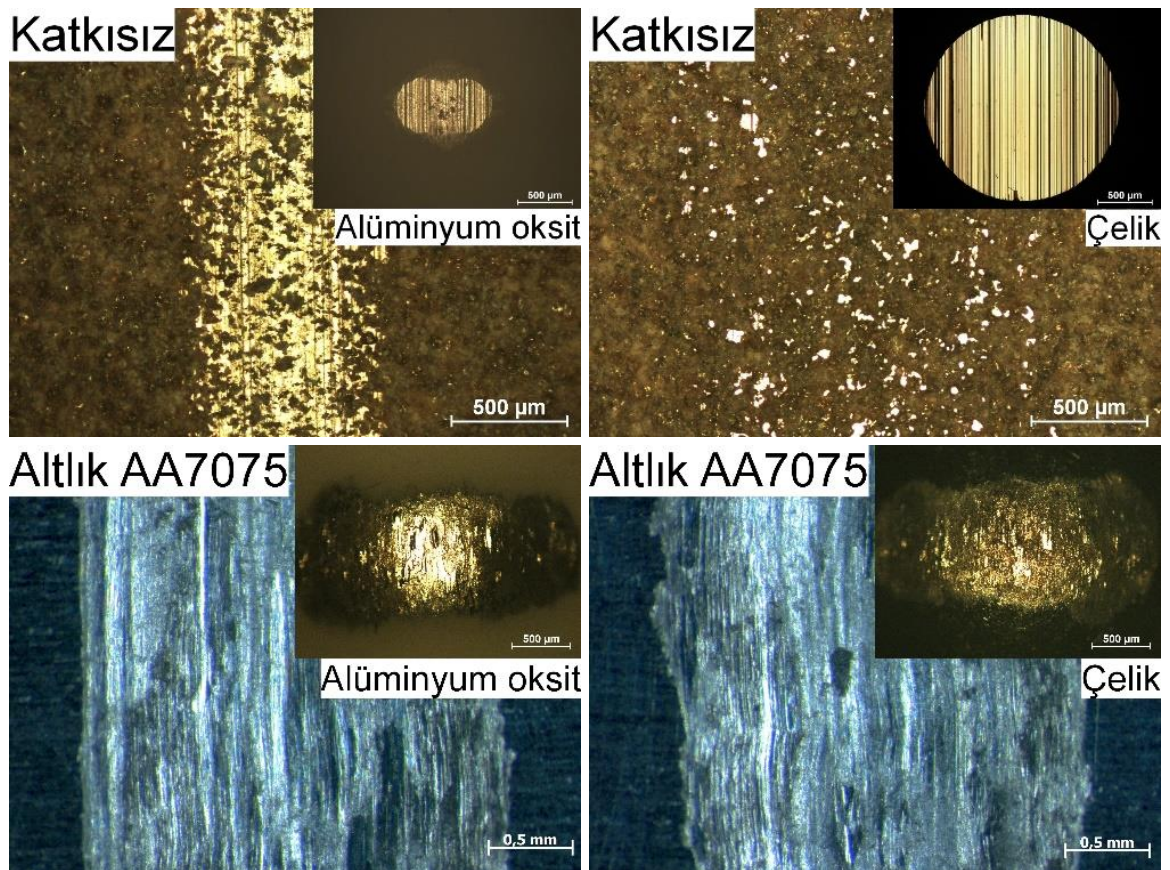

Şekil 9. Katkısız Kaplama ve Altlık Alaşımın Yüzeylerinde Çelik ve Alüminyum

Oksit Bilyelerin Oluşturduğu Aşınma İzlerinin Optik Mikroskop Görüntüleri

\section{Sonuçlar}

Alüminyum oksit, silisyum oksit, wolfram-titanyum karbür ve titanyum karbür parçacıklar ilave edilerek hazırlanan çözeltilerde, plazma elektrolitik oksidasyon (PEO) yöntemiyle AA7075 alaşımı üzerine seramik kaplamalar geliştirilmiş, mikroyapı incelemesi, faz analizi, sertlik ölçümü, sürtünme ve aşınma testi başarılı bir şekilde uygulanmış ve sonuçlar aşağıda sunulmuştur.

1. Altlık alaşımı üzerinde oluşturulan katkısız ve parçacık takviyeli PEO kaplamaların kalınlık değerleri 46-107 $\mu$ m aralığında değişmektedir. En kalın kaplamalar silisyum oksit parçacık takviyeli çözeltilerde üretilmiştir.

2. Kaplamaların yoğun alt tabaka ve gözenekli üst tabakadan oluştuğu belirlenmiştir.

3. Faz analizi sonucunda tüm kaplamalarda $\gamma-\mathrm{Al}_{2} \mathrm{O}_{3}$ ve az miktarda $\alpha$ $\mathrm{Al}_{2} \mathrm{O}_{3}$ olduğu tespit edilmiştir. SO kaplamalarda amorf silisyum oksidin yapıya 
Savunma Sanayisinde Aşırı Koşullara Maruz Kalan

Hafif Yapısal Malzemelerin Yüzey Modifikasyonu

katılmasıyla müllit fazının oluştuğu belirlenmiştir. WTC-1 kaplamada çözelti içerisindeki wolfram-titanyum karbür parçacıkların yapısal değişime uğramadan yapıya dahil olduğu ortaya çıkmıştır.

4. Kaplamaların sertlik değerlerinin kaplama/altlık arayüzeyine yakın yoğun tabakada yüksek, yüzeye doğru ilerledikçe artan gözeneklilik sebebiyle düşük çıktığ1 tespit edilmiştir.

5. PEO kaplamaların altlık alaşımın aşınma direncini önemli ölçüde arttırdığı tespit edilmiştir. Yüksek sertlikte kalın oksit tabakasının yük taşıma kapasitesini arttırdığı ve bu sayede aşınma hızını azalttığı sonucuna varılmıştır.

\section{Extended Summary}

\section{Introduction}

Aluminum and aluminum alloys, an an essential material of today's industry, are widely used in many fields such as electronics, aerospace, defense industries owing to its high specific strength, low density and easy forming. However, low wear resistance limits the application fields of aluminum and its alloys. In addition, aluminum and its alloys are susceptible to corrosion due to their chemical composition. In order to minimize these disadvantages mentioned above, alloying, heat treatment and surface coating processes are applied (Davis, 1993; Necşulescu, 2011). Surface coating processes among these processes are widely used to protect aluminum alloys against environmental influences and to improve surface properties (Shibe and Chawla 2014).

On the other hand, PEO, or micro-arc oxidation (MAO), has become the focus of attention of researchers in recent years as it is an environmentally sensitive coating method that allows the coating of complex shaped parts and does not contain acidic solution. This process includes the deposition and growth of an oxide layer on substrate alloys. Due to the high hardness of the ceramic oxide coating, a significant increase in the wear resistance of the substrate metal is observed (Yerokhin et al., 1999). In this study, ceramic coatings were developed on AA7075 alloy by plasma electrolytic oxidation (PEO) method in different solutions prepared by adding aluminum oxide, silicon oxide, wolfram-titanium carbide and titanium carbide particles. 


\section{Materials and Method}

\section{Particle Size Measurement}

Malvern Panalytical brand Zetasizer Nano ZS device was used for the dimensional measurement of the particles supplied by the manufacturer. Prior to measurement, aluminum oxide, titanium carbide, wolfram-titanium carbide and titanium carbide particles were added into $50 \mathrm{ml}$ of pure water solution containing $0.5 \mathrm{~g} / \mathrm{l}$ sodium dodecyl sulfate (SDS) and mixed with ultrasonic agitator for 10 $\min$.

\section{PEO Coating Process}

Specimens of $10 \mathrm{~mm}$ thickness and $25 \mathrm{~mm}$ diameter were obtained by cutting a cylindrical bar made of AA7075 aluminum alloy using $\mathrm{SiC}$ abrasive disc. The surfaces of the specimens were grinded with 240,400, 800 and 1200 grit sand papers respectively and then ultrasonically cleaned in acetone and dried with hot air. After specimen preparation, PEO treatment was conducted using a bipolar AC power source.

\section{Structural Analysis of Coatings}

The surface roughness of the coatings was measured using the Ambios XP2 surface profilometer. JEOL 6060 scanning electron microscope (SEM) was used to investigate the surface morphology of the coatings and to obtain the cross sectional images. Energy dispersive x-ray spectrometry (EDX) was used for chemical analysis of coatings. The phase analysis of the particles and coatings was conducted by the Rigaku D-Max X-ray diffractometer.

\section{Hardness Measurement}

The hardness values of the substrate alloy and the coatings were measured using Shimadzu microVickers hardness tester with an applied load of $0.025 \mathrm{~kg}$.

\section{Wear Test}

Dry sliding wear tests were performed against $100 \mathrm{Cr} 6$ steel and aluminum oxide balls with a diameter of $6 \mathrm{~mm}$, at a constant load of $10 \mathrm{~N}$, and with a stroke 
Savunma Sanayisinde Așırı Koşullara Maruz Kalan

Hafif Yapısal Malzemelerin Yüzey Modifikasyonu

length of $10 \mathrm{~mm}$. Total wear distance and sliding velocity were determined as 200 $\mathrm{m}$ and $0.06 \mathrm{~m} / \mathrm{s}$, respectively.

\section{Test Results and Discussion}

\section{Particle Size Measurement}

The mean sizes of silicon oxide, aluminum oxide, wolfram-titanium carbide and titanium carbide particles were measured as $272 \mathrm{~nm}, 1493 \mathrm{~nm}, 417 \mathrm{~nm}$ and $195 \mathrm{~nm}$, respectively.

\section{XRD analysis}

According to XRD analysis results, the silicon oxide material was found to be amorphous. It has been also determined that the aluminum oxide material involves mostly $\alpha-\mathrm{Al}_{2} \mathrm{O}_{3}$ and very little amount of $\beta-\mathrm{Al}_{2} \mathrm{O}_{3}$. Titanium carbide and wolfram-titanium carbide materials are consisted of $\mathrm{TiC}$ and $\mathrm{C}_{5} \mathrm{Ti}_{4} \mathrm{~W}$ crystalline phases.

In all coatings, it has been observed that the semi-stable $\gamma-\mathrm{Al}_{2} \mathrm{O}_{3}$ phase was formed by oxidation of the aluminum substrate. The semi-stable $\gamma-\mathrm{Al}_{2} \mathrm{O}_{3}$ is transformed into a thermodynamically stable $\alpha-\mathrm{Al}_{2} \mathrm{O}_{3}$ phase above $1050{ }^{\circ} \mathrm{C}$ (Lamouri et al., 2017). It has been determined that the amount of $\alpha-\mathrm{Al}_{2} \mathrm{O}_{3}$ is less than that of $\gamma-\mathrm{Al}_{2} \mathrm{O}_{3}$. The negatively charged aluminum oxide particles surrounded by SDS molecules were moved to the anode surface during the PEO process, resulting in an increase in the amount of $\alpha-\mathrm{Al}_{2} \mathrm{O}_{3}$ in the structure of the AO-1 and AO-3 coatings. Mullite is determined in the coatings produced in the silicon oxide particle-containing solution.

\section{SEM analysis}

In general, it has been observed that the coatings consist of a porous and rough outer layer, and a dense inner layer. The surface roughness increased with increased particle concentration in the solution. The presence of silicon in all coatings shows that silicate ions $\left(\mathrm{SiO}_{3}{ }^{2-}\right)$ in the base electrolyte is highly incorporated into the structure. The incorporation of amorphous silicon oxide particles and silicate ions resulted in increased silicon contents in SO-1 and SO-3 coatings. As the ratio of $\alpha-\mathrm{Al}_{2} \mathrm{O}_{3}$ particles in the solution increased, the aluminum 
content in $\mathrm{AO}$ coatings increased. In WTC- 1 and TC- 1 coatings, it has been observed that wolfram and titanium-containing particles are included in the coating structures.

It has been found that the amount of silicon increased in the regions close to the surface then decreased towards the substrate alloy. According to this, it has been revealed that more particles accumulated in the regions close the coating surfaces.

\section{Hardness Measurement Results}

Compared to the substrate AA7075 alloy, it has been observed that the hardness values increased significantly due to the presence of crystalline ceramic phases in coating structures. It has been determined that the hardness of inner layer is higher than the outer layer of coatings. This is related to the increased porosity of the coating close to the surface regions.

\section{Wear Test Results}

The uncoated AA7075 alloy has been found to suffer from excessive material loss during the wear test since it has lower surface hardness compared to steel and aluminum oxide balls. On the other hand, the coatings showed considerably lower wear rates than substrate alloy due to their high hardness and high load bearing capacity. It has been observed that the porous outer layer of SO coatings is easily worn out during sliding test and resulted in increased wear rate as compared with other coatings. The lowest wear rate was obtained with TC-1 coatings.

\section{Conclusion}

The thickness of the PEO coatings with and without particle-reinforcement ranges from 46 to $107 \mu \mathrm{m}$. Thickest coating is produced in silicon oxide particlecontaining solution with a concentration of $3 \mathrm{~g} / \mathrm{l}$. The coatings are generally consisted of a dense inner layer and porous outer layer. It has been determined that PEO coatings significantly increase the wear resistance of the substrate alloy. The lowest wear rate of coating was obtained with the titanium carbide particle addition into the base solution. 
Savunma Sanayisinde Așırı Koşullara Maruz Kalan

Hafif Yapısal Malzemelerin Yüzey Modifikasyonu

\section{Kaynakça}

\section{Kitaplar}

Davis, J.R. (1993). Aluminum and Aluminum Alloys. Cleveland: ASM International.

McColm, I. (1990). Ceramic Hardness. New York: Springer US.

\section{Makaleler}

Arunnellaiappan, T., Arun, S., Hariprasad, S., Gowtham, S., Ravisankar, B., Rama Krishna, L., Rameshbabu, N. (2018). Fabrication of corrosion resistant hydrophobic ceramic nanocomposite coatings on PEO treated AA7075. Ceramics International, 44, 874-884.

Fatimah, S., Kamil, M.P., Kwon, J.H., Kaseem, M., Ko,Y.G. (2017). Dual incorporation of $\mathrm{SiO}_{2}$ and $\mathrm{ZrO}_{2}$ nanoparticles into the oxide layer on 6061 $\mathrm{Al}$ alloy via plasma electrolytic oxidation: Coating structure and corrosion properties. Journal of Alloys and Compound, 707, 358-364.

Kollenberg. W., Schneider, H. (1989). Microhardness of Mullite at Temperatures to $1000^{\circ}$. Journal of the American Ceramic Society, 72(9), 1739-1740.

Krell, A., Schädlich, S. (2001). Nanoindentation hardness of submicrometer alumina ceramics. Materials Science and Engineering: A, 307(1-2), 172181.

Lamouri, S., Hamidouche, M., Bouaouadja, N., Belhouchet, H., Garnier, V., Fantozzi, G., Trelkat, J.F. (2017). Control of the $\gamma$-alumina to $\alpha$-alumina phase transformation for an optimized alumina densification, Boletín de la Sociedad Española de Cerámica y Vidrio, 56(2), 47-54.

Nasiri Vatan, H., Adabi, M. (2017). Investigation of wear and corrosion resistance of nanocomposite coating formed on AZ31B $\mathrm{Mg}$ alloy by plasma electrolytic oxidation. The International Journal of Surface Engineering and Coatings, 95(6), 308-315.

Necşulescu, D.A. (2011). The Effects of Corrosion on The Mechanical Properties of Aluminium Alloy 7075-T6. U.P.B. Sci. Bull. Series B, 73(1), 223-229. 
Pitchford, J.E., Stearn, R.J., Kelly, A., Clegg, W.J. (2004). Effect of Oxygen Vacancies on the Hot Hardness of Mullite. Journal of the American Ceramic Society, 84(5), 1167-1168.

Shibe, V., Chawla, V. (2014). A Review of Surface Modification Techniques in Enhancing the Erosion Resistance of Engineering Components. International Journal of Research in Mechanical Engineering \& Technology, 4,92-95.

Xin, S., Song, L., Zhao, R., Hu, X. (2006) Composition and thermal properties of the coating containing mullite and alumina, Materials Chemistry and Physics, 97(1), 132-136.

Yerokhin, A.L., Nie, X., Leyland, A., Matthews, A., Dowey, S.J. (1999). Plasma electrolysis for surface engineering. Surface and Coatings Technology, $122,73-93$. 